\title{
Effects of Temperature, Humidity, and Wounding on Development of Phytophthora Rot of Cucumber Fruit
}

\author{
L. L. Granke and M. K. Hausbeck, Department of Plant Pathology, Michigan State University, East Lansing, MI 48824
}

\begin{abstract}
Granke, L. L., and Hausbeck, M. K. 2010. Effects of temperature, humidity, and wounding on development of Phytophthora rot of cucumber fruit. Plant Dis. 94:1417-1424.

The effects of temperature $\left(10,15,20,25,30\right.$, and $\left.35^{\circ} \mathrm{C}\right)$ and relative humidity $(\sim 35,60,70,80$, and $100 \%$ ) on development of Phytophthora fruit rot, caused by Phytophthora capsici, of pickling cucumber (Cucumis sativus) were investigated in controlled growth chamber studies. The effect of wounding on disease development was characterized for small (2.0 to $2.5 \mathrm{~cm}$ diameter $\times 8$ to $9 \mathrm{~cm}$ long), medium ( 3.0 to $4.0 \mathrm{~cm}$ diameter $\times 12.0$ to $13.0 \mathrm{~cm}$ long), and large $(>4.5 \mathrm{~cm}$ diameter $\times>14 \mathrm{~cm}$ long) pickling cucumbers. Lesions developed on cucumbers incubated at all temperatures tested except 10 and $35^{\circ} \mathrm{C}$. Disease severity was greatest on cucumbers incubated at $25^{\circ} \mathrm{C}$ at 4 days postinoculation (dpi). Lesions formed on cucumbers incubated at all relative humidities tested. The diameter of water-soaking and pathogen growth increased as the incubation relative humidity increased. Wounding lessened age-related resistance in pickling cucumbers. The diameter of water-soaking was similar for all wounded cucumbers at 4 dpi regardless of fruit size. Sporangial production was greater on small and medium fruits than on large fruits. These results indicate that $P$. capsici is capable of infecting cucumbers over a wide range of temperature and relative humidity conditions. Wounding increases the susceptibility of pickling cucumbers to $P$. capsici.
\end{abstract}

The oomycete plant pathogen Phytophthora capsici Leonian causes fruit rot, foliar blight, and crown and root rot of many vegetable crops in the Cucurbitaceae and Solanaceae (8), as well as snap and lima bean (Phaseolus vulgaris L., Phaseolus lunatus L.) $(5,11)$. Fruit rot of cucumber (Cucumis sativus L.) is common when weather is favorable for disease development and P. capsici is present (13). Michigan is the largest producer of pickling cucumbers in the United States (2), and many of the major growing areas of the state are infested with $P$. capsici. Entire fields of mature cucumber fruits and semi truck loads of harvested cucumbers may be lost due to fruit rot (13).

Environmental conditions such as temperature and relative humidity influence development of diseases caused by Phytophthora spp. (7). In a previous study looking at the effect of zoospore suspension temperature on infection of pickling cucumber, cucumbers became infected when floated in zoospore suspensions held at 9 to $32^{\circ} \mathrm{C}$. Cucumbers were infected when held in 3 liters of water containing $\geq 3 \times 10^{7}$ zoospores that was incubated at 9 or $12^{\circ} \mathrm{C}$, but not when the water contained

Corresponding author: M. K. Hausbeck

E-mail: hausbec1@msu.edu

Accepted for publication 24 August 2010.

doi:10.1094/PDIS-04-10-0258

(C) 2010 The American Phytopathological Society $\sim 3 \times 10^{5}$ zoospores. Cucumbers were infected at water temperatures ranging from 19 to $32^{\circ} \mathrm{C}$, regardless of the number of zoospores present, although the infection incidence was much less when the water contained $\sim 3 \times 10^{5}$ zoospores (12). The effect of incubation temperature on development of Phytophthora fruit rot of cucumber has not been previously characterized. In pepper, disease incidence and lesion length were greatest when inoculated fruits were incubated at $27^{\circ} \mathrm{C} \mathrm{(3)}$.

The effect of relative humidity on lesion development on cucumber has not been previously characterized, but the effect of relative humidity on sporangial production has been reported. Hausbeck and Lamour (13) observed that sporangial production on slicing cucumber fruits was greater at 60 and $80 \%$ relative humidity than at $>90 \%$.

Previous work has shown that fruit age is an important factor for infection of and sporangial production on cucumbers (10) and peppers (4). Gevens et al. (10) found that fruits $\geq 14$ days postpollination old were usually symptom-free, and fruits $\leq 10$ days postpollination old displayed both water-soaked lesions and pathogen sporulation. This resistance could also be defined using size as a surrogate for age. Oversized pickling cucumbers with a diameter $>4.5 \mathrm{~cm}$ and length $>14 \mathrm{~cm}$ were more often symptom-free than smaller fruits following inoculation. Pickling cucumbers with a diameter $\geq 3.5 \mathrm{~cm}$ had much lower disease ratings than smaller fruits in the same study. Age-related resis- tance was also observed for a slicing cucumber variety, with more water-soaking and sporulation being observed on the smallest and presumably youngest fruits tested (10). A similar phenomenon has been observed for pepper fruits, where unwounded young pepper fruits became more severely diseased than mature pepper fruits (4). However, when the peppers were wounded, lesion expansion was similar for all fruits, regardless of age (4). It is currently unknown whether or not wounding is able to negate age-related resistance in cucumber.

Understanding the roles environment and mechanical injury play in the development of Phytophthora fruit rot could provide growers with information to minimize the factors most likely to encourage postharvest fruit losses due to $P$. capsici. The objective of our study was to elucidate the effects of temperature, relative humidity, and wounding on development of Phytophthora rot of cucumber and on pathogen growth and sporulation on infected cucumber fruits.

\section{MATERIALS AND METHODS}

Generation of host and pathogen material. Cucumber fruits ('Vlaspik') were grown at the Michigan State University (MSU) Plant Pathology Farm, East Lansing, a site without a history of $P$. capsici. Cucumber plants were treated weekly with either Previcur Flex (propamocarb hydrochloride, 0.93 liters a.i./ha, Bayer CropScience) or Bravo Weather Stik (chlorothalonil, 1.26 liters a.i./ha, Syngenta Crop Protection) to control downy and powdery mildews and were fertilized and watered according to standard production practices. For the experiments investigating the effects of temperature and relative humidity on disease development, fruits were handharvested when 2 to $3 \mathrm{~cm}$ in diameter, washed in a $2 \%$ bleach $(0.12 \% \mathrm{NaClO})$ solution, rinsed with tap water, surfacedisinfested with a 20\% bleach (1.24\% $\mathrm{NaClO}$ ) solution for $5 \mathrm{~min}$, rinsed with tap water, air-dried, and placed into the incubation chambers prior to inoculation with a $10-\mu$ droplet of water containing $\sim 2.5 \times$ $10^{4}$ zoospores. Incubation chambers consisted of clear polystyrene boxes with lids $(23 \times 10 \times 32 \mathrm{~cm}$, Potomac Display, Hampstead, MD).

For the wounding experiments, cucumbers were hand-harvested at three sizes: small (2 to $2.5 \mathrm{~cm}$ diameter $\times 8$ to $9 \mathrm{~cm}$ long), medium ( 3 to $4 \mathrm{~cm}$ diameter $\times 12$ to 
$13 \mathrm{~cm}$ long), and large $(>4.5 \mathrm{~cm}$ diameter $x>14 \mathrm{~cm}$ long). Fruit size was chosen based on the work of Gevens et al. (10) to represent different levels of age-related resistance to $P$. capsici. Cucumbers were washed and surface-disinfested as described above and placed into aluminum trays prior to treatment and inoculation. High humidity was maintained in the aluminum trays by placing wet paper towels along the edges of the tray, which was sealed with plastic film and tape following inoculation.

Actively growing cultures of $P$. capsici isolates SP98 and OP97 were used (isolate notation refers to the culture collection maintained in the laboratory of M. K. Hausbeck at MSU). The cultures were derived from long-term stock cultures and passed through cucumber fruits according to the methods of Quesada-Ocampo et al. (16) before use. Isolates were maintained and zoospore suspensions created as described previously (12).

Effects of temperature on disease development. Two incubation chambers with the capacity to hold 12 cucumbers each were placed into a growth chamber set at $10,15,20,25,30$, or $35^{\circ} \mathrm{C}$ (16/8 day/night photoperiod and $\sim 95 \mathrm{mE}$ of light intensity). Air from a TopFin XP-125 aquarium pump (PetSmart, Phoenix, AZ) was humidified by pumping it through an aquarium airstone submerged in 1.5 liters of distilled water in a 2-liter Erlenmeyer filter flask. Air exiting the flask was routed to the incubation chambers using clear tygon tubing. A small piece of wet paper towel was added to each box to ensure high relative humidity $(\sim 100 \%)$ was maintained. Air exited through a $6.4-\mathrm{mm}$ hole that was drilled into the opposite side of the chamber lid.

For each temperature treatment, 24 fruits were used (12 per incubation chamber, six replicate fruits per time point). Each fruit was inoculated with a single 10$\mu \mathrm{l}$ droplet of zoospore suspension containing $\sim 2.5 \times 10^{4}$ zoospores (isolate SP98). A single $10-\mu$ d droplet of water was placed on each of six control cucumbers that were incubated at room temperature $(\sim 25 \pm$ $2^{\circ} \mathrm{C}$ ) and high relative humidity to ensure that the cucumber fruits used in the experiment were not infected with $P$. capsici at the onset of the experiment. Six fruits were chosen arbitrarily and removed from each temperature treatment at 1,2,3, and 4 days postinoculation (dpi) for evaluation.

Each fruit was evaluated for watersoaked lesion diameter (visible dark discoloration of the fruit surface) and the diameter of pathogen growth in the lesion. The number of sporangia in each lesion was determined as follows: If sporangia could be observed in a lesion via stereomicroscopy (Leica M165C, Wetzlar, Germany), the area of pathogen growth was carefully excised with a razor blade and placed into $1 \mathrm{ml}$ of water in a $2.2-\mathrm{ml} \mathrm{mi-}$ crocentrifuge tube. The tube was vortexed for $70 \mathrm{~s}$, plant material removed using forceps, and number of sporangia in the tube estimated using a hemacytometer. If sporangia could be observed via stereomicroscopy, but could not be detected via the method above, the sporangial suspension was concentrated by centrifuging the tube for $5 \mathrm{~min}$ at $14,000 \mathrm{rpm}$. The supernatant was removed and the sporangia were resuspended in $100 \mu \mathrm{l}$ of distilled water and estimated using a hemacytometer.

When lesions were apparent on fruits but no sporangia were observed, tissue sections from the margin of each lesion were plated onto UCV8 $(160 \mathrm{ml}$ of unclarified V8 juice, $840 \mathrm{ml}$ of distilled water, $30 \mathrm{mM} \mathrm{CaCO}_{3}$, and $1.5 \%$ agar) plates amended with $25 \mathrm{ppm}$ of benomyl, 100 ppm of ampicillin, $30 \mathrm{ppm}$ of rifampicin, and $100 \mathrm{ppm}$ of pentachloronitrobenzene (BARP) to confirm infection with $P$. capsici. When fruits appeared healthy, three tissue sections were excised from under the point of inoculation and plated onto BARP-amended UCV8. Plates were incubated at room temperature $\left(\sim 25 \pm 2^{\circ} \mathrm{C}\right)$ under constant fluorescent lighting for 3 to 5 days and observed using a compound microscope. P. capsici was confirmed using morphological characteristics according to the Phytophthora spp. key by Waterhouse (20). The resulting $P$. capsici colonies were transferred to fresh UCV8, and isolates were characterized for mating type and mefenoxam sensitivity (14) to confirm they had the same phenotype as the inoculum. The experiment was conducted twice.

The temperature and relative humidity in each incubation chamber was monitored for the duration of each experiment using WatchDog model 450 data loggers (Spectrum Technologies, Plainfield, IL). Data loggers were set to record temperature $\left({ }^{\circ} \mathrm{C}\right)$ and relative humidity $(\%)$ at 10 -min intervals. The accuracy ratings of the data loggers were $\pm 0.6^{\circ} \mathrm{C}$ and $\pm 3 \%$ relative humidity. Data were downloaded into a computer at the end of each experiment. Since lighting was not continuous, slight photoperiodic fluctuations in temperature and relative humidity were observed.

Effects of relative humidity on disease development. Five incubation chambers were placed into a growth chamber maintained at $25^{\circ} \mathrm{C}$ with fluorescent lighting (16/8 day/night photoperiod and $95 \mathrm{mE}$ of light intensity). Glycerol/water solutions $(60,70,80$, and $100 \%$ relative humidities) and a saturated salt solution (potassium acetate, $35 \%$ relative humidity) were prepared as described in Forney and Brandl (9) and Winston and Bates (21). One liter of solution was added to each incubation chamber to control the relative humidity of that chamber $(\sim 35,60,70,80$, or $100 \%)$. Eight $2.5 \mathrm{~cm}$ diameter $\times 3 \mathrm{~cm}$ tall pieces of PVC pipe (stilts) were placed into the solution in the bottom of each incubation chamber. A $29 \times 20 \mathrm{~cm}$ screen made of two layers of hardware mesh ( $0.7 \mathrm{~cm}$ squares) was suspended above the glycerol or salt solution by the stilts. A piece of clear tygon tubing was inserted into a 6.4- $\mathrm{mm}$ hole that had been drilled into the lid of the incubation chamber and connected to a TopFin XP-125 aquarium pump to circulate the air within the chamber. The temperature and relative humidity (Table 1) in each chamber were monitored as described above. For each relative humidity treatment, 12 fruits (six replicate fruits per time point) were inoculated with a single $10-\mu l$ droplet of zoospore suspension containing $\sim 2.5 \times 10^{4}$ zoospores. Six fruits were chosen arbitrarily and removed from each incubation chamber at 3 and $4 \mathrm{dpi}$, and evaluated for disease as described above.

Table 1. Average, maximum, and minimum relative humidities observed in incubation chambers over the course of this study on development of Phytophthora fruit rot of pickling cucumbers using Phytophthora capsici isolates SP98 and OP97

\begin{tabular}{|c|c|c|c|c|c|c|}
\hline \multirow[b]{3}{*}{ Goal RH ${ }^{\mathbf{a}}$} & \multicolumn{6}{|c|}{ Relative humidity } \\
\hline & \multicolumn{3}{|c|}{ Isolate SP98 } & \multicolumn{3}{|c|}{ Isolate OP97 } \\
\hline & Mean $\pm \mathbf{S E}^{\mathbf{b}}$ & Max. $^{c}$ & Min. $^{d}$ & Mean \pm SE & Max. & Min. \\
\hline 35 & $32.0 \pm 0.2$ & 33.0 & 20.7 & $35.7 \pm 0.2$ & 47.5 & 20.7 \\
\hline 60 & $59.3 \pm 0.1$ & 69.5 & 48.9 & $61.4 \pm 0.2$ & 74.3 & 48.6 \\
\hline 70 & $67.3 \pm 0.1$ & 76.2 & 60.5 & $67.6 \pm 0.1$ & 72.5 & 56.6 \\
\hline 80 & $81.1 \pm 0.1$ & 86.6 & 72.2 & $79.1 \pm 0.1$ & 85.7 & 71.6 \\
\hline 100 & $99.1 \pm 0.0$ & 100.0 & 86.6 & $97.5 \pm 0.1$ & 100.0 & 89.8 \\
\hline
\end{tabular}

\footnotetext{
${ }^{\mathrm{a}} \mathrm{RH}=$ relative humidity $(\%)$.

${ }^{\mathrm{b}}$ Mean $\pm \mathrm{SE}=$ mean relative humidity \pm standard error.

${ }^{\mathrm{c}}$ Max. $=$ maximum relative humidity.

$\mathrm{d}$ Min. $=$ minimum relative humidity .
} 
Six control cucumbers were treated as described above. Three independent experiments were conducted for each isolate (SP98 and OP97).

Effect of wounding on size-related resistance. For each cucumber size chosen, a shallow wound ( 1 to $2 \mathrm{~cm}$ deep) was created in the center of 20 surfacedisinfested fruits using a sterilized 1-mmdiameter dissecting needle, and 20 fruits remained unwounded. All of the fruits were inoculated with a single $10-\mu$ droplet of water containing $\sim 2.5 \times 10^{4}$ zoospores in the center of the fruit, over the wound, if present. Ten unwounded and ten wounded cucumbers were inoculated with isolate SP98, and the remaining cucumbers were inoculated with OP97. Inoculated fruits were incubated for 4 days at room temperature $\left(\sim 25 \pm 2{ }^{\circ} \mathrm{C}\right)$ in aluminum trays sealed with plastic film under constant fluorescent lighting and were evaluated as described above. Six control cucumbers were treated as described above. The experiment was conducted three times.

Statistical analyses. All statistical analyses were performed using the SAS statistical package version 9.1 (SAS Institute, Inc., Cary, NC). Data from 10 and $35^{\circ} \mathrm{C}$ were removed prior to analysis, as no symptoms or signs of the disease were observed on fruits incubated at these temperatures. Averages were calculated for the measurements of lesion and pathogen growth diameters prior to statistical analysis. A split-plot design was used for all of the studies conducted. For the temperature studies, temperature was the main plot effect and time was the subplot effect. For the relative humidity studies, isolate was the main plot effect and relative humidity was the subplot effect. For the wounding studies, treatment (fruit size $\times$ isolate) was the main plot effect and wounding was the subplot effect. After checking for significant differences between runs of the same experiment, data from multiple runs of the same experiment were pooled for statistical analysis. Using the Proc Mixed procedure of SAS, data were subjected to splitplot analysis of variance (ANOVA, $P \leq$ 0.05 ), and Fisher's protected LSD was used for separation of means $(P \leq 0.05)$ when effects were significant. Prior to analyses, the number of sporangia produced in each lesion was log transformed for all experiments, and the water-soaked lesion diameter was $\log$ transformed for the wounding experiments to fulfill the assumption of normally distributed residuals.

The Proc LOESS procedure of SAS was used to perform loess nonparametric regression analyses to model the relationship between temperature, incubation time, and each of the response variables (watersoaked lesion diameter, pathogen growth diameter, and sporangial production). The correlation between predicted and actual measures of disease severity was used as measures of goodness-of-fit of the loess nonparametric regression model.

\section{RESULTS}

No symptoms or signs of disease were observed on fruits incubated at 10 or $35^{\circ} \mathrm{C}$, and the pathogen was never recovered from fruits incubated at $35^{\circ} \mathrm{C}$. P. capsici was recovered from a small $(<10 \%)$ number of cucumbers incubated at $10^{\circ} \mathrm{C}$, indicating a latent infection (data not shown). At $1 \mathrm{dpi}$, symptoms were not apparent on any of the fruits, regardless of incubation temperature (Fig. 1A). However, the pathogen could be isolated from fruits at 1 dpi, suggesting that infection had already occurred (data not shown). Water-soaked lesions were apparent on fruits incubated at 20 to $30^{\circ} \mathrm{C}$ by $2 \mathrm{dpi}$ (Fig. 1B), but pathogen growth and sporulation were not visible. By 3 dpi, pathogen growth and sporulation in the lesions could be observed and measured (Fig. 1C and D). Up to $2.7 \times 10^{6}$ sporangia were quantified from a single lesion at 4 dpi.

The interaction between temperature and time was significant for water-soaked lesion diameter, pathogen growth diameter, and sporangial production in the lesion $(P$ $<0.0001)$. Partitioned analysis of the least squares means for the interaction showed differences in water-soaked lesion diameter and pathogen growth diameter for the different incubation temperatures for fruits incubated 3 or 4 dpi $(P<0.0054)$, but not on fruits incubated for 1 or 2 dpi $(P>$ 0.22 ). Differences in sporangial production in the lesions were only observed at $4 \mathrm{dpi}$ $(P<0.0001)$. The water-soaked lesion diameter was greatest for fruits incubated 4 dpi at 20 or $25^{\circ} \mathrm{C}$. At $3 \mathrm{dpi}$, the watersoaked lesion diameter was similar for fruits incubated at 20,25 , or $30^{\circ} \mathrm{C}$ (Fig. $2 \mathrm{~A})$. The pathogen growth diameter and sporangial production was greatest for fruits incubated at $25^{\circ} \mathrm{C}$ at $4 \mathrm{dpi}$ (Fig. 2B and C). At 3 dpi, the diameter of pathogen growth was greatest for fruits incubated at $30^{\circ} \mathrm{C}$, and sporangial production was similar for fruits incubated at 20,25 , or $30^{\circ} \mathrm{C}$. The results of loess regression suggested that $25^{\circ} \mathrm{C}$ was the most favorable temperature for disease development at 4 dpi (Fig. $2 \mathrm{D}$ to $\mathrm{F}$ ), in agreement with the results from ANOVA analyses. The main effect of time was significant $(P<0.0001)$ for all of the response variables, but temperature was not $(P>0.07)$. Water-soaked lesion diameter, pathogen growth diameter, and sporangial production were greatest at 4 dpi (Fig. 2A to C).

No significant interaction was noted between relative humidity, isolate, and time $(P>0.5731)$, but there was a significant interaction between relative humidity and time for all three measures of disease severity $(P<0.0437)$. The diameter of watersoaking and pathogen growth increased as the relative humidity increased at both 3 and 4 dpi (Fig. 3A and B). Sporangial pro- duction in the lesions was greater for cucumbers incubated at $\geq 60 \%$ than for fruits incubated at $35 \%$ relative humidity at 3 or 4 dpi (Fig. 3C). Sporangia were not produced (Fig. 3C), but lesions did form (Fig. $3 \mathrm{~A}$ ) when inoculated fruits were incubated at $35 \%$ relative humidity. The interaction between isolate and time was not significant $(P>0.2424)$, nor was the main effect of isolate $(P>0.0813)$. The main effect of time was significant $(P<0.0001)$, and greater diameters of water-soaking and pathogen growth and more sporangia were observed on fruits incubated for $4 \mathrm{dpi}$ (Fig $3 \mathrm{~A}$ to $\mathrm{C})$. The interaction between isolate and relative humidity was not significant for the water-soaked or pathogen growth diameter $(P>0.0750)$, but it was significant for sporangial production in the lesion $(P=0.0059)$. For isolate SP98, sporulation was lowest in lesions on fruits incubated at $35 \%$ relative humidity, and the number of sporangia produced was significantly different than for any of the other relative humidities tested. For OP97, sporulation was also lowest at $35 \%$, but a statistically similar number of sporangia were produced in lesions on cucumbers incubated at $60 \%$ relative humidity (Fig. 3D). When the main effect of relative humidity $(P<$ 0.0001) was examined, the water-soaked lesion diameter increased as the relative humidity level increased (Fig. 3A). Pathogen growth diameter followed a similar trend, except that the diameters for 70 and $80 \%$ relative humidity were statistically similar (Fig. 3B).

The interaction between treatment (fruit size $\times$ isolate) and wounding (wounded or not) was significant for water-soaked lesion diameter $(P<0.0001)$, pathogen growth diameter $(P<0.0001)$, and sporangial production in the lesion $(P=0.0017)$ Small and medium fruits inoculated with SP98 displayed the largest water-soaked lesion diameters among the unwounded fruits. The smallest water-soaked lesions were observed on unwounded large fruits inoculated with isolate OP97 (Fig. 4A). When fruits were wounded, similar watersoaked lesion diameters were observed for fruits of all sizes, and the diameter of water-soaking was greater than for unwounded fruits of the same size and isolate combination (Fig. 4A). A similar relationship was also observed for pathogen growth in the lesion (Fig. 4B) and sporulation (Fig. 4C), with lesions on wounded fruits showing more pathogen growth and sporulation than those on corresponding unwounded fruits. While pathogen growth was greater on wounded large fruits than on unwounded large fruits, the pathogen growth diameter was greater still on unwounded small and medium fruits (Fig. 4B). Pathogen growth diameter and sporulation were greatest on wounded small or medium cucumbers inoculated with SP98 (Fig. 4B and C). Sporangia were not produced in lesions on large fruits, except for 
wounded large fruits inoculated with SP98 (Fig. 4C).

Overall, symptom expression was greater on fruits inoculated with SP98 than on fruits inoculated with OP97 (Fig. 4A to $\mathrm{C}$ ), and the main effect of treatment (size $\times$ isolate) was significant $(P<0.0012)$. All of the wounded fruits inoculated with SP98 had a greater water-soaked lesion diameter than any of the unwounded fruits, regardless of isolate (Fig. 4A). In addition, wounded fruits inoculated with OP97 had lesions of similar size to the largest lesions observed on the unwounded fruits (Fig. 4A). Interestingly, the difference in virulence observed between isolates on unwounded fruits was less obvious when the fruits were wounded (Fig. 4A). However, sporangial production was much greater with SP98 than with OP97, regardless of whether or not the fruits were wounded (Fig. 4C). Wounded fruits showed more severe symptoms and signs of disease than unwounded fruits (Fig. 4A to C), and the effect of wounding was significant $(P<$ 0.0001). Hence, wounding appeared to lessen age-related resistance.

\section{DISCUSSION}

This study showed that $P$. capsici is capable of infecting cucumber fruits over a wide range of temperature and relative humidity conditions. In addition, wounding appeared to lessen age-related resistance to $P$. capsici in pickling cucumber. Careful handling, storage, and transport of pickling cucumbers and temperatures $<15^{\circ} \mathrm{C}$ are recommended based on the results of this study. The current recommended storage temperature of $\sim 12^{\circ} \mathrm{C}$ (6) seems appropriate in light of these results.

Growth chamber studies showed that $P$. capsici is capable of infecting and causing disease on cucumber fruits incubated at 15 to $30^{\circ} \mathrm{C}$. By $2 \mathrm{dpi}$, water-soaking, the first symptom of Phytophthora rot, was present in this study, as has been observed in previous studies in cucumber (13). A limited number of cucumbers appeared to have a latent infection when incubated at $10^{\circ} \mathrm{C}$ in this study. The minimum growth temperature for $P$. capsici in culture medium has been reported as $10^{\circ} \mathrm{C}(8)$, and it is not surprising that symptoms were not observed at this temperature. When pickling cucumbers were floated in a large volume of zoospore suspension held at 9 or $12^{\circ} \mathrm{C}$, removed from the suspension, and then incubated at room temperature, cucumbers became infected when the suspension contained $\geq 3 \times 10^{7}$ zoospores, but not when the suspension contained $\sim 3 \times 10^{5}$ zoo- spores (12). Hence, the current study and a previous study both suggest that only limited disease may occur at low temperatures $\left(\leq 12^{\circ} \mathrm{C}\right)$. Cucumbers incubated at $35^{\circ} \mathrm{C}$ did not show symptoms of disease in this study, and the pathogen was not recovered from these fruits, even though $P$. capsici has a growth maximum of $>35^{\circ} \mathrm{C}$ in culture medium $(8,18,19)$. Both of the isolates used in this study grew readily on UCV8 when incubated at $35^{\circ} \mathrm{C}$ (data not shown).

Symptoms of disease were apparent on cucumbers incubated at 20 to $30^{\circ} \mathrm{C}$ in our study. In addition, limited lesions formed at $15^{\circ} \mathrm{C}$. Symptoms and signs of disease were most apparent on cucumbers incubated at $25^{\circ} \mathrm{C}$, similar to what was previously reported as ideal for infection and lesion development on pepper fruits $\left(27^{\circ} \mathrm{C}\right)$ (3) and leaves $\left(23^{\circ} \mathrm{C}\right)$ (17). Sporangia did not form in lesions on cucumber fruits in our study following exposure to temperatures $\leq 15^{\circ} \mathrm{C}$ or $\geq 35^{\circ} \mathrm{C}$, suggesting limited or no sporangial production at these temperatures. As would be expected, symptoms and signs of disease became more pronounced the longer the cucumbers were incubated.

Lesion expansion and pathogen growth in the lesion increased as the relative humidity increased. When fruits were incu-

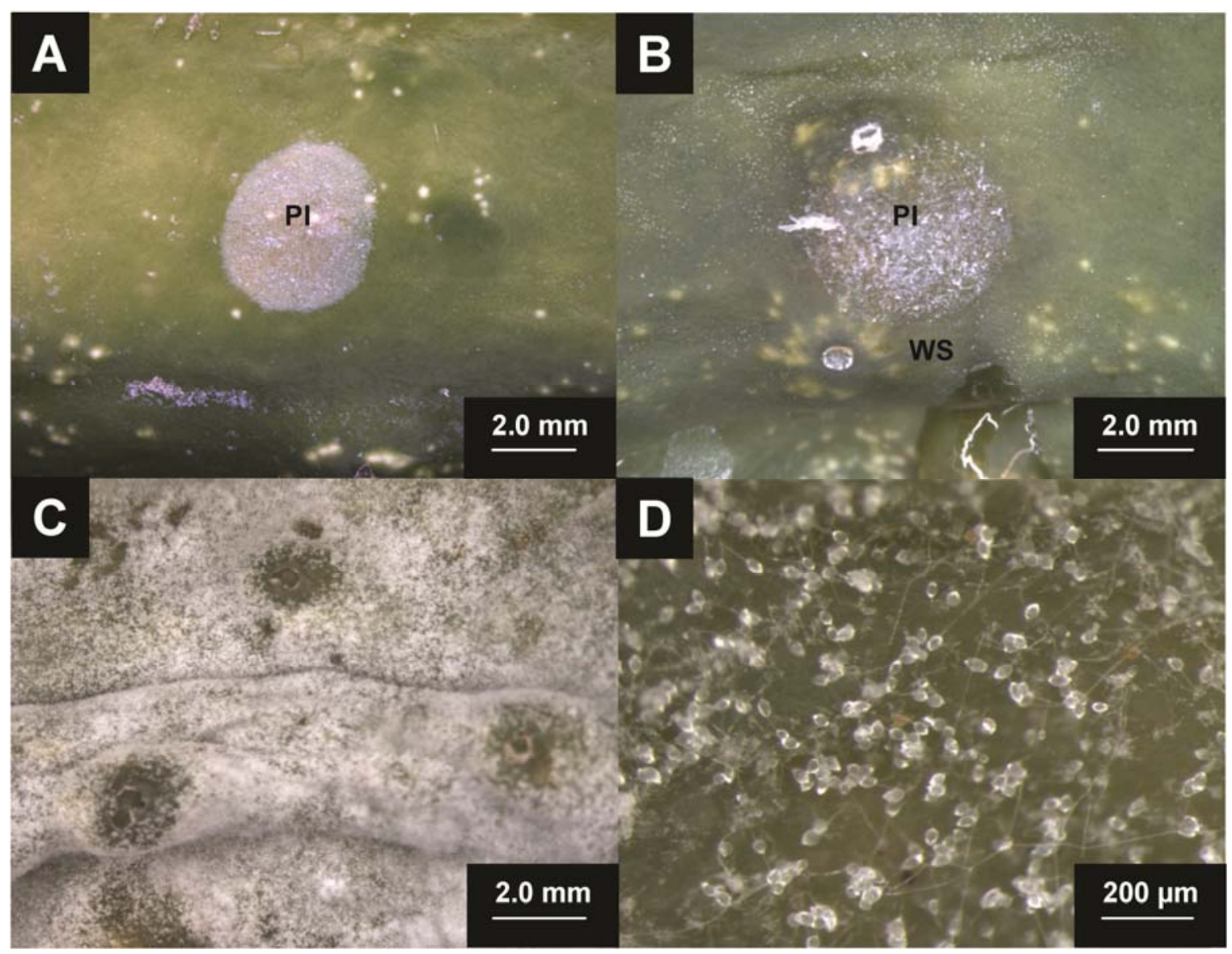

Fig. 1. A, No symptoms of Phytophthora fruit rot were observed on cucumber fruits incubated at any temperature $\left(25^{\circ} \mathrm{C}\right.$ shown) at 1 day postinoculation (dpi) with Phytophthora capsici zoospores. B, Water-soaking (WS) was apparent on fruits incubated at 20 to $30^{\circ} \mathrm{C}$ at 2 dpi $\left(30^{\circ} \mathrm{C}\right.$ shown), but pathogen growth outside the point of inoculation (PI) was not observed. Significant pathogen growth and sporulation were apparent in water-soaked lesions on fruits incubated at 20 to $30^{\circ} \mathrm{C}$ at (C and D) 3 and 4 dpi. 
bated at $35 \%$ relative humidity in the current study, no sporangia were detected in the lesions. However, P. capsici was able to produce thousands of sporangia in some of the lesions on fruits incubated at $\geq 60 \%$ relative humidity. While similar numbers of sporangia were produced at $\geq 60 \%$ at 3 dpi, significantly more sporangia were produced at $60 \%$ relative humidity than at $\geq 70 \%$ at 4 dpi. Hausbeck and Lamour (13) found that sporangial production was greater at 60 and $80 \%$ relative humidity
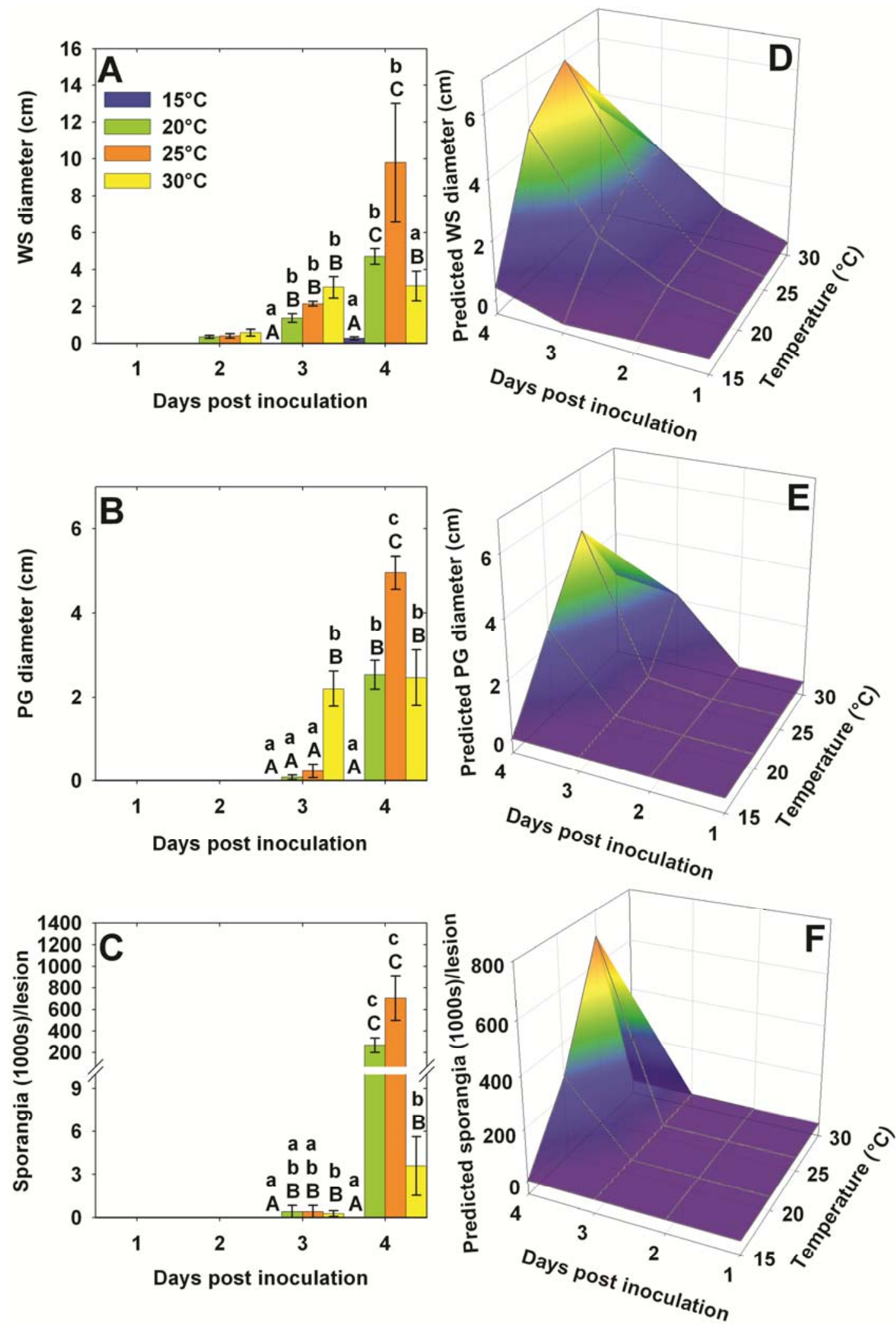

Fig. 2. Mean A, water-soaked (WS) lesion diameter, $\mathbf{B}$, pathogen growth (PG) diameter, and $\mathbf{C}$, number of sporangia produced on pickling cucumbers after $1,2,3$, or 4 days incubation at $15,20,25$, or $30^{\circ} \mathrm{C}$ following inoculation with Phytophthora capsici zoospores. Note differences in y-axes and break in the yaxis from 10 to 100 in C. Error bars represent standard error. Bars that share letters are not significantly different within a time point (days postinoculation [dpi], lowercase letters) or between time points (capital letters). Response surface of the predicted D, water-soaked lesion diameter, E, pathogen growth diameter, and $\mathbf{F}$, number of sporangia per lesion as a function of temperature and time (dpi). Plots were generated using predicted values from fitted loess nonparametric regression models. Models were fitted using 32 observations ( 2 experiments $\times 16$ treatment combinations). 
than at $>90 \%$ at 5 dpi on slicing cucumber fruits, in partial agreement with the current study. It is interesting to note that while $60 \%$ was optimal for sporangial production by isolate SP98, this relationship was not as clear for OP97. For OP97, sporulation was greater at 60 to $80 \%$ relative humidity and was reduced at $100 \%$ relative humidity, in agreement with the results from Hausbeck and Lamour (13), who also used isolate OP97.

In the current study, all of the symptoms and signs of disease were greater on wounded fruits than on unwounded fruits.
Wounding has been shown to increase $P$. capsici disease severity in Fraser fir (16), pepper plants (1), and pepper fruits (4) as well. In our study, small and medium unwounded cucumbers showed more severe symptoms and signs of disease than large fruits, as has been previously noted for pickling and slicing cucumbers (10) and pepper fruits (4). Gevens et al. (10) found that older, oversized pickling cucumbers had a lower disease incidence, and no sporangia were detected in lesions on pickling cucumbers $\geq 14 \mathrm{~cm}$ long. We did not detect sporangia in lesions on unwounded large fruits at 4 dpi, but sporangia were formed on large fruits $(\geq 14 \mathrm{~cm}$ long) that were wounded prior to inoculation. For isolate SP98, sporangial production on wounded large fruits was reduced compared to unwounded and wounded small and medium fruits. Sporangial production was generally poor on fruits inoculated with OP97 as compared to SP98, but wounding increased sporangial production.

When cucumbers were unwounded, small and medium fruits had larger lesion diameters than large fruits. However, wounding appeared to negate differences
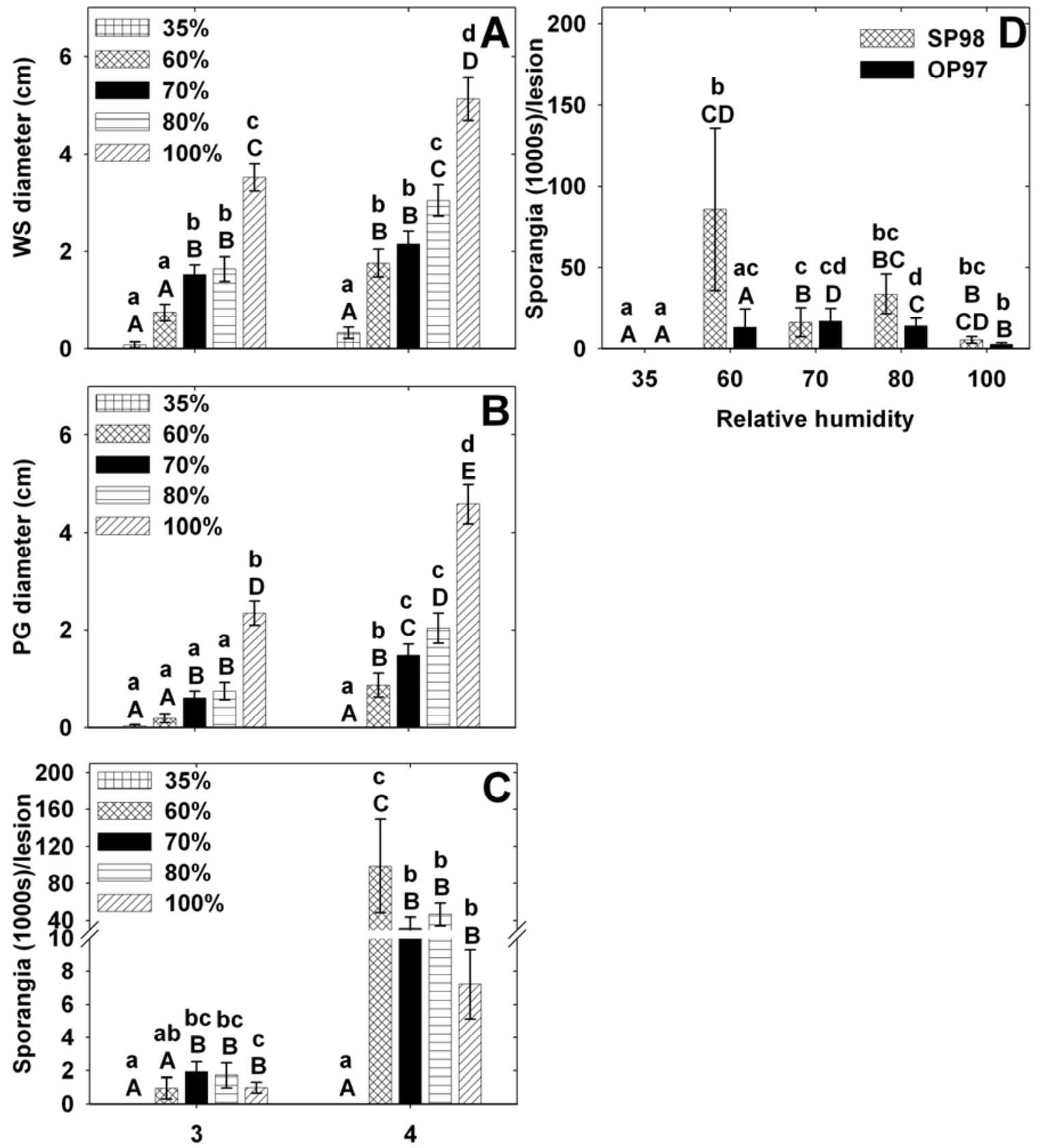

\section{Days post inoculation}

Fig. 3. Mean A, water-soaked (WS) lesion diameter, B, pathogen growth (PG) diameter, and $\mathbf{C}$, number of sporangia produced on pickling cucumber fruits after 3 or 4 days incubation at 35, 60, 70,80, or 100\% relative humidity following inoculation with Phytophthora capsici zoospores. Bars that share letters are not significantly different within a time point (days postinoculation [dpi], lowercase letters) or between time points (capital letters). D, Number of sporangia produced on cucumbers incubated at $35,60,70,80$, or $100 \%$ relative humidity by isolate. Bars that share letters are not significantly different for a specific isolate (lowercase letters) or between conditions of relative humidity (capital letters). Error bars represent standard error. 
in lesion diameter; water-soaked lesion diameters were similar for wounded fruits inoculated with the same isolate, regardless of fruit size. In pepper, wounding has been found to negate age-related resistance, and disease progress was similar on wounded fruits, regardless of age (4). Interestingly, while differences in virulence
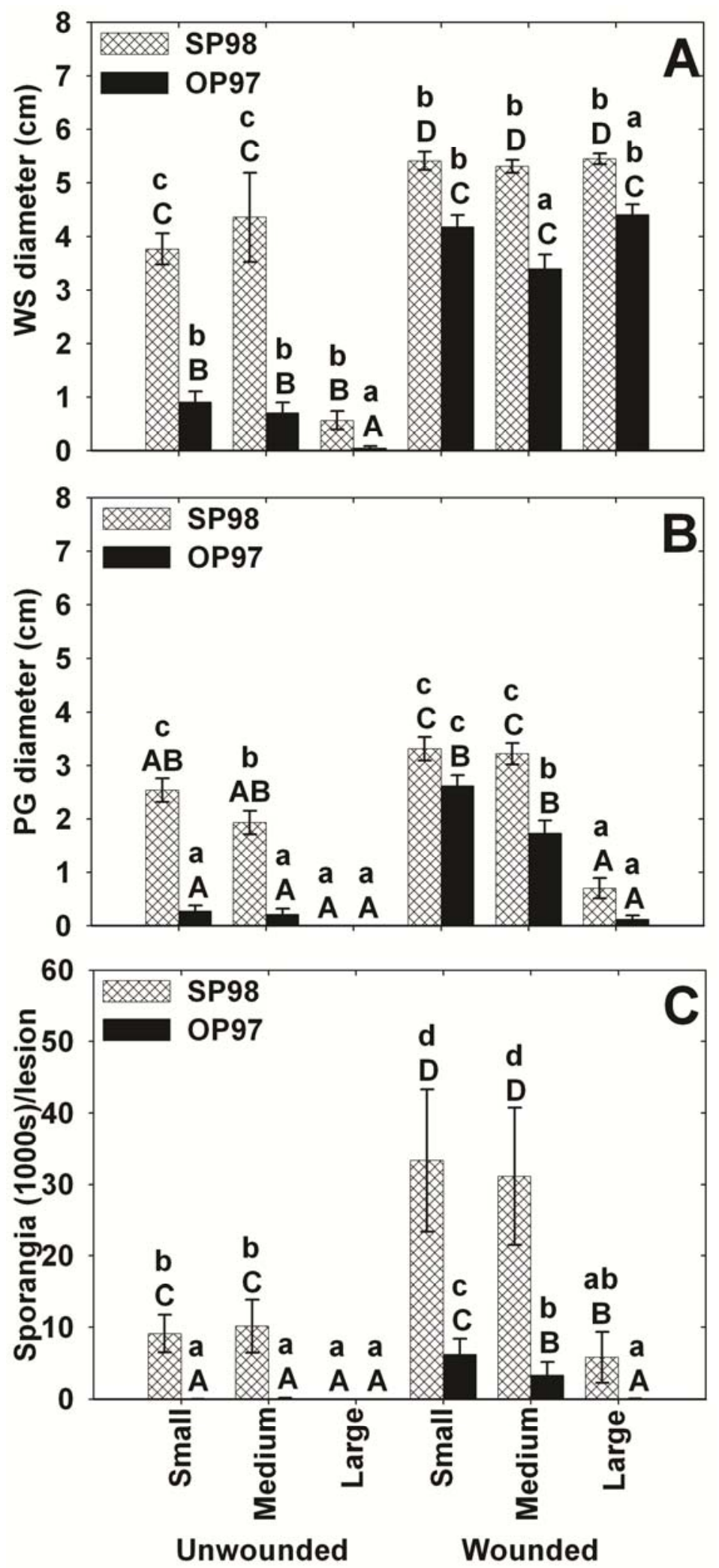

Fig. 4. Mean A, water-soaked (WS) lesion diameter, B, pathogen growth (PG) diameter, and $\mathbf{C}$, number of sporangia produced on unwounded and wounded pickling cucumber fruits of various sizes (small, medium, or large) 4 days postinoculation (dpi) with a droplet of water containing Phytophthora capsici zoospores. Note differences in the y-axes. Means that share letters are not significantly different for an isolate (lowercase letters) or between treatments (fruit size $\times$ wounding, capital letters). Error bars represent standard error.

by isolate were obvious for unwounded fruits, differences in virulence on wounded cucumbers were more subtle for watersoaked lesion diameter and pathogen growth diameter, suggesting that virulence may be at least partially affected by the ability of the different pathogen isolates to penetrate the fruit surface. There were obvious differences between isolates for sporangial production on both unwounded and wounded fruits.

In summary, $P$. capsici is a dynamic pathogen that is capable of infecting and causing disease on pickling cucumbers over a wide range of temperature and relative humidity conditions. Because there is a lag time of days following inoculation before symptom expression and sporulation, storing and transporting potentially infected fruits under cool temperatures $\left(<15^{\circ} \mathrm{C}\right)$ is necessary to slow disease progression so that fruits will not rot in transit. Wounding has been shown to lessen the effects of agerelated resistance; thus, careful handling of the fruits is key for cucumbers of all ages. Cucumber fruits may be dropped distances of $>3 \mathrm{~m}$ during harvest and handling, which constitutes a major source of mechanical injury for the fruits (15). If injured fruits are exposed to inoculum after wounding, disease is more likely to occur.

\section{ACKNOWLEDGMENTS}

This research is based upon work supported by the USDA CSREES Special Research Grant Awards 2009-34572-19990 and 2008-34572-19339, MAES multistate project NE-1035, and the Pickle and Pepper Research Committee of MSU, Pickle Packers International, Inc. We thank S. Windstam, A. Lebeis, M. Wood, and R. Heslip for technical assistance, W. Wang for help with statistical analyses, and S. Linderman and L. Quesada-Ocampo for critical review of the manuscript.

\section{LITERATURE CITED}

1. Adorada, D. L., Biles, C. L., Liddell, C. M., Fernandez-Pavia, S., Waugh, K. O., and Waugh, M. E. 2008. Disease development and enhanced susceptibility of wounded pepper roots to Phytophthora capsici. Plant Pathol. 49:719-726.

2. Anonymous. 2009. Vegetables Annual Summary, 01.27.2010. U.S. Dep. Agric. Natl. Agric. Stat. Serv. Online publication.

3. Biles, C. L., Bruton, B. D., Wall, M. M., and Rivas, M. 1995. Phytophthora capsici zoospore infection of pepper fruit in various physical environments. Proc. Okla. Acad. Sci. 75:1-5.

4. Biles, C. L., Wall, M. M., Waugh, M., and Palmer, H. 1993. Relationship of Phytophthora fruit rot to fruit maturation and cuticle thickness of New Mexican-type peppers. Phytopathology 83:607-611.

5. Davidson, C. R., Carroll, R. B., Evans, T. A., Mulrooney, R. P., and Kim, S. H. 2002. First report of Phytophthora capsici infecting lima bean (Phaseolus lunatus) in the mid-Atlantic region. Plant Dis. 86:1049.

6. DeEll, J. R., Vigneault, C., and Lemerre, S. 2000. Water temperature for hydrocooling field cucumbers in relation to chilling injury during storage. Postharv. Biol. Technol. 18:27-32.

7. Duniway, J. M. 1983. Role of physical factors in the development of Phytophthora diseases. Pages 175-187 in: Phytophthora: Its Biology, Taxonomy, Ecology, and Pathology. D. C. Erwin, S. Bartnicki-Garcia, and P. H. Tsao, 
eds. American Phytopathological Society, St. Paul, MN.

8. Erwin, D. C., and Ribeiro, O. K. 1996. Phytophthora Diseases Worldwide. American Phytopathological Society, St. Paul, MN.

9. Forney, C. F., and Brandl, D. G. 1992. Control of humidity in small controlled-environment chambers using glycerol-water solutions. HortTechnology 2:52-54.

10. Gevens, A. J., Ando, K., Lamour, K. H., Grumet, R., and Hausbeck, M. K. 2006. A detached cucumber fruit method to screen for resistance to Phytophthora capsici and effect of fruit age on susceptibility to infection. Plant Dis. 90:1276-1282.

11. Gevens, A. J., and Hausbeck, M. K. 2005. Phytophthora capsici isolated from snap beans is pathogenic to cucumber fruit and soybean. (Abstr.) Phytopathology 95:S162.

12. Granke, L. L., and Hausbeck, M. K. 2010.
Effects of temperature, concentration, age, and algaecides on Phytophthora capsici zoospore infectivity. Plant Dis. 94:54-60.

13. Hausbeck, M. K., and Lamour, K. H. 2004. Phytophthora capsici on vegetable crops: Research progress and management challenges. Plant Dis. 88:1292-1303.

14. Lamour, K. H., and Hausbeck, M. K. 2003. Susceptibility of mefenoxam-treated cucurbits to isolates of Phytophthora capsici sensitive and insensitive to mefenoxam. Plant Dis. 87:920-922.

15. Miller, A. R. 2003. Harvest and handling injury: Physiology, biochemistry, and detection. Pages 177-208 in: Postharvest Physiology and Pathology of Vegetables. J. A. Bartz and J. K. Brecht, eds. Marcel Dekker Inc., New York.

16. Quesada-Ocampo, L. M., Fulbright, D. W., and Hausbeck, M. K. 2009. Susceptibility of Fraser fir to Phytophthora capsici. Plant
Dis. 93:135-141.

17. Schlub, R. L. 1983. Epidemiology of Phy tophthora capsici on bell pepper. J. Agric. Sci. 100:7-11.

18. Stamps, D. J. 1985. Phytophthora capsici. Commonw. Mycol. Inst. Descriptions of Pathogenic Fungi and Bacteria No. 836.

19. Tsao, P. H. 1988. The identities, nomenclature and taxonomy of Phytophthora isolates from black pepper. Pages 185-211 in: Proc. Int Pepper Commun. Workshop Joint Res. Control Black Pepper Dis. Y. R. Sarma and T. Premkumor, eds. National Research Centre for Spices, Calicut, Kerala, India.

20. Waterhouse, G. 1963. Key to the Species of Phytophthora de Bary. Commonwealth Mycological Society, Kew, England.

21. Winston, P. W., and Bates, D. H. 1960. Saturated solutions for the control of humidity in biological research. Ecology 41:232-237. 